Original Article

\title{
Scavenging activity nano complex compounds of kelor (Moringa oleifera Lamk.) leaves and seeds
}

\author{
Rafida Azizah, Tintrim Rahayu, Ari Hayati, Gatra Ervi Jayanti* \\ Biology Department, Faculti of Mathematics and Natural Sciences, University of Islam Malang
}

\begin{abstract}
Moringa oleifera Lamk. is a good source of natural antioxidants because it contains various types of antioxidant compounds such as ascorbic acid, flavonoids, phenolics, and carotenoids. Those antioxidant components forming complex structure have transitional metal as central compound, which have free radical scavenging activity. This study aims to determine the active compounds that act as scavenger in leaves and seeds of $M$. oleifera. The possible compound found in leaves-seeds is elaborated by in silico analysis, using Dr. Duke's Phytochemical and Ethnobotanical Databases, by mean Pass online, and HitPick software. The results of in silico analysis 3 compounds identified in the leaves that had a high antioxidant role, namely betacarotene, kaempferol, quercetin, and 2 compounds in seeds that had a high antioxidant role, namely alpha-tocopherol, beta-carotene. The results of this study indicate that the antioxidant activity of the 3 treatments had differences effectiveness of antioxidants. All of these antioxidants has ability to bind transitional metal to form free radical scavenger.
\end{abstract}

Keywords: Moringa oleifera Lamk., In silico, complex scavenger

Received: 15 October 2020 Revised: 23 December 2020 Accepted: 23 December 2020

\section{Introduction}

The development of science makes it easier for humans to cope with all their necessities of life. One of them is the application of the in silico method in the search for compounds and prediction of compound potential. In silico is a method of using computer equipment, one of which is to assist in the field of pharmacology (Ekins, 2007).

Reductionistic activity (simplification) is the way that humans consider the easiest way to get knowledge from a study. Systems in life are complex objects of study. Therefore, the theory of complexity is developed from the physics of science in the middle of the 20th century (Sumitro, 2011). Complexity science deals with complex systems and problems that are dynamic, unpredictable, and multi-dimensional, and consists of a set of relationships and interconnected parts (Miles, 2009).

One of the fields of complexity science that is being developed is the nano complex. The advantage of using nanotechnology is that it can change surface properties and particle size so that herbal medicines can be targeted at organs with high security. Besides, the active compounds that have been released can be controlled so that side effects can be minimized, and nano-sized herbal medicines can be used in high concentrations (Dewandari et al., 2013). The drying of an anti-cancer drug of proprietary nature (Nano sized) was carried out by a freeze-drying technique to get a free-flowing powder. Apart from enhancing the systemic

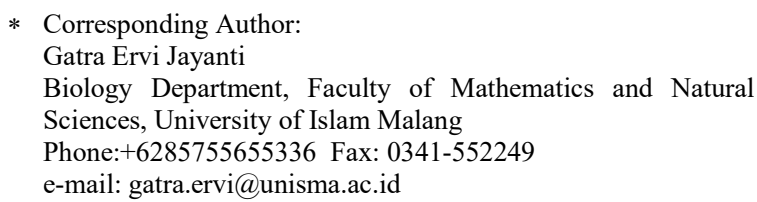

administration, Nano particulate systems can also be used for site-specific drug delivery, thus alleviating unwanted toxicity due to nonspecific drug distribution, thus resulting in improved patient compliance and providing enhanced clinical outcomes (Patil et al., 2010).

Humans are mostly exposed to endogenous and exogenous sources of free radicals every day. The sources are UV light, cigarette smoke, ionizing radiation, exposure to certain organic solvents, pollutants, industrial waste, or just metabolism (Boonchum et al., 2011). The attendance of free radicals in humans can conduct to degenerative diseases such as cancer, coronary heart disease, and Alzheimer's disease (Pezzuto et al., 2002). Free radicals are atoms or molecules containing at least one unpaired electron in their outer orbitals. The unpaired electrons result in paramagnetic properties which urge to transform the molecule into a stable form. Electrons in every orbital must be paired and these paired electrons must rotate on the axis of the opposite direction (Sukmaningsih et al., 2018). Free radicals can be shed with antioxidant compounds. Natural antioxidants are considered less toxic and more potent than synthetic antioxidants and are therefore preferred over their synthetic counterparts (butylated hydroxyanisole and butylated hydroxytoluene) (Boonchum et al., 2011). Natural antioxidants such as tocopherols, flavonoids, vitamin $\mathrm{C}$, and other phenolic compounds are known to exist in several plants (Laandrault et al., 2001).

There is a difference between a single antioxidant and an antioxidant complex. A single antioxidant can turn into a pro-oxidant in the presence of transition metal ions and free radicals can accumulate. During interaction with a single antioxidant, metal ions can be reduced, oxidized, and reduced back (redox cycle) to produce reactive oxygen species. Conversely, complex antioxidants can 
trap free radicals without the formation of new radical species due to a large number of electrons on their surface (Jayanti et al., 2018).

Phytochemicals are non-nutritional phytochemicals with preservative or disease-preventing character. The family of moringa consists of phytochemicals such as beta-sitosterol, kaempferitrin, zeatin, quercetin, kaempferol, rhamnetin and rhamnose, and typical compounds called isothiocyanates and glucosinolates (Fahey, 2005). Moringa oleifera Lamk. also contains some phytochemicals. All parts of $M$. oleifera are said to have beneficial properties that contribute to its versatility and value as a medicinal plant (Padayachee, 2019).

Research on $M$. oleifera leaves and seeds has been widely carried out, but no one has researched a combination of $M$. oleifera leaves and seeds, so this topic will be very interesting to study. Previous studies have suggested that extracts obtained from leaves were likely to show higher antioxidant activity than extracts from seeds. Vyas et al (2015) had revealed that flower extract displayed the highest antioxidant activity followed by leaf, root, gum, bark, and seed. It has also reported that M. oleifera leaves had almost twice the TPC (Total Phenolic Compounds) and threefold the TFC (Total Flavonoid Content) of the vegetables. Reducing power and DPPH radical scavenging ability of $M$. oleifera leaves were also much higher than those of the selected vegetables (Pakade et al., 2013). Therefore, this study aimed to observe the active compound of $M$. oleifera leaves and seeds through in silico analysis and to examine the antioxidant activity of $M$. oleifera leaves, seeds, combination leaves-seeds.

\section{Methods}

\section{Plant materials}

The leaves of $M$. oleifera were obtained from the Garden University of Islam Malang. The leaves that used were the old and young leaves and obtained from the $M$. oleifera tree with $2 \mathrm{~m}$ high. The seeds of $M$. oleifera that used were dry. The determination of plant species was carried out by a study of plant taxonomy literature (Flora and Spermatophyta books).

\section{Preparation of nano complex plant sample}

The leaves of $M$. oleifera were separated from the stem and branches. The seeds of $M$. oleifera were separated from the seed coat. The leaves were blended and the seeds were pounded. In the first treatment, $10 \mathrm{~g}$ of diluted leaves were dissolved with distilled water up to $100 \mathrm{ml}$. The second treatment, $10 \mathrm{~g}$ of diluted seeds were dissolved with $100 \mathrm{ml}$ of distilled water. The third treatment is a mixture of leaves and seeds, every $5 \mathrm{~g}$ is taken and dissolved in distilled water up to $100 \mathrm{ml}$. All of the plant samples were centrifuged with a centrifuge (PLC Series 03, Taiwan) at $2800 \mathrm{rpm}$ speeds for $15 \mathrm{~min}$. Speed in the centrifugation process also affects the size of the molecules to be formed. The higher of the centrifuge speed result the smaller the molecular size. Nanogold particles at a centrifuge speed of $3000 \mathrm{rpm}$ have yields $70 \mathrm{~nm}$ (Nanopartz, 2020). The step gradients were created in a centrifuge tube by layering different concentration of solutions, and the nano particle solutions were layered on top of the density gradient (Kowalczyk et al., 2020).

The supernatant of each treatment was freeze-dried with a freeze dryer (Alpha 1-2 LD Plus, Germany) for 24 $\mathrm{h}$. The sample solution was made in $4 \mathrm{mg} / \mathrm{ml}$. Freezedrying has become a welcomed idea especially in the pharmaceutical and other bioproduct industries and gradually becoming a well-utilized processing method in the food industries owing to the assumptions of product quality good perform. The initial freezing process involves the formation of ice nuclei which are dependent on factors such as the cooling rate, interfacial energy, and the interfacial morphology or the nano structure of foreign bodies (Oyinloye et al., 2020).

\section{In silico analysis}

Active compounds in $M$. oleifera plants were searched through Dr. Duke's Phytochemical and Ethnobotanical Databases. Then, the identity of the active compound was searched through the PubChem website. Each active compound has a molecular formula and canonical SMILES. Canonical SMILES used to predict the active compound potency that searched with the Pass online website. Canonical SMILES also used to predict the target of an active compound. The active compounds that have a $\mathrm{Pa}$ value of more than 0.7 were predicted to be active as an antioxidant.

\section{2,2-Diphenyl-1-picrylhydrazil (DPPH) assay}

The DPPH assay was conducted using the method from Wibawa et al (2018) with some modifications to determine antioxidant activity. 3 types of the sample of $M$. oleifera were used to make a comparison of DPPH scavenging activity. $0.0015 \mathrm{~g}$ DPPH (Sigma Aldrich, USA) was dissolved in $25 \mathrm{ml}$ methanol (Merck, Germany). Briefly, $1 \mathrm{ml}$ of the sample of $M$. oleifera were put in a test tube, then were added with $3 \mathrm{ml} \mathrm{DPPH}$ $0.1 \mathrm{mM}$. These mixtures were incubated in a dark place for 30 minutes and measured the absorbances by spectrophotometer UV-Vis (Thermo Scientific Genesys 150, USA) with $517 \mathrm{~nm}$ wavelength. The radical scavenging activity was calculated using the formula:

Scavenging Activity $\%=(\mathrm{Ac}-\mathrm{As}) / \mathrm{Ac} \times 100$

Ac: control absorbance (DPPH)

As: sample absorbance (DPPH + sample)

The comparison of antioxidant activity between 3 types of nano complex samples (leaves, seeds, combination leaves, and seeds of $M$. oleifera) was analyzed by percent of scavenging activity. The result of the scavenging activity percentage each sample was analyzed with ANOVA statistical test through JAMOVI application.

\section{Observation of nano complex plant sample}

The observation of the nano complex plant sample using a microscope (Olympus BX43, Germany). The samples observed were nano complex samples from $M$. oleifera leaves. The difference observed was the cells from each sample before and after freeze-drying. 


\section{Results}

Based on the in silico analysis leaves of M. oleifera contained 8 identified active compounds, and seeds of $M$. oleifera contained 27 identified active compounds. The identified active compounds were searched canonical SMILES to predict the potential of an active compound. The active compound in the leaves and seeds of $M$. oleifera were performed in Tables 1 and 2. The major component of leaves and seeds of $M$. oleifera were shown by the compound that has a Pa value of more than 0.7. The major component in M. oleifera was showed in Table 3. The major component is the major of compound that will be active to scavenging the free radicals, and is a constituent component of Nano complex antioxidant compounds from M. oleifera leaves and seeds.

Table 1. Prediction of the potential active compounds from M. oleifera leaves

\begin{tabular}{cccc}
\hline No & Active compound & Pa value & Pi value \\
\hline 1 & Ascorbic-Acid & 0.928 & 0.003 \\
2 & Beta-Carotene & 0.775 & 0.004 \\
3 & Caffeic-Acid & 0.603 & 0.005 \\
4 & Kaempferol & 0.856 & 0.003 \\
5 & Niazimin & 0.383 & 0.014 \\
6 & Prolamine & 0.161 & 0.115 \\
7 & Quercetin & 0.872 & 0.003 \\
8 & Tocopherols & 0.927 & 0.003 \\
\hline
\end{tabular}

Table 2. Prediction of the potential active compounds from $M$. oleifera

\begin{tabular}{|c|c|c|c|}
\hline No & Active compound & $\mathrm{Pa}$ value & Pi value \\
\hline 1 & 2.4-Methylenecholesterol & 0.157 & 0.094 \\
\hline 2 & $\begin{array}{c}\text { 4-( } \alpha \text {-L-rhamnosyloxy) } \\
\text { benzyl glucosinolate }\end{array}$ & 0.319 & 0.02 \\
\hline 3 & $\begin{array}{l}\text { 4-( } \alpha \text {-L-rhamnosyloxy) } \\
\text { benzyl isothiocyanate }\end{array}$ & 0.533 & 0.005 \\
\hline 4 & Alpha-Tocopherol & 0.967 & 0.002 \\
\hline 5 & Arachidic-Acid & 0.222 & 0.045 \\
\hline 6 & Behenic-Acid & 0.222 & 0.045 \\
\hline 7 & Beta-Carotene & 0.775 & 0.004 \\
\hline 8 & Beta-Sitosterol & 0.178 & 0.072 \\
\hline 9 & Brassicasterol & 0.276 & 0.028 \\
\hline 10 & Campestanol & 0.178 & 0.071 \\
\hline 11 & Campesterol & 0.182 & 0.068 \\
\hline 12 & Cholesterol & 0.198 & 0.056 \\
\hline 13 & Clerosterol & 0.306 & 0.022 \\
\hline 14 & Delta-5-Avenasterol & 0.196 & 0.057 \\
\hline 15 & Delta-7-Avenasterol & 0.19 & 0.061 \\
\hline 16 & Delta-Tocopherol & 0.843 & 0.003 \\
\hline 17 & Ergostadienol & 0.269 & 0.03 \\
\hline 18 & Gadoleic-Acid & 0.283 & 0.026 \\
\hline 19 & Gamma-Tocopherol & 0.927 & 0.003 \\
\hline 20 & Lignoceric-Acid & 0.222 & 0.045 \\
\hline 21 & Myristic-Acid & 0.222 & 0.045 \\
\hline 22 & Oleic-Acid & 0.283 & 0.026 \\
\hline 23 & Palmitic-Acid & 0.222 & 0.045 \\
\hline 24 & Stearic-Acid & 0.222 & 0.045 \\
\hline 25 & Stigmastanol & 0.174 & 0.075 \\
\hline 26 & Stigmasterol & 0.215 & 0.048 \\
\hline 27 & Tocopherols & 0.927 & 0.003 \\
\hline
\end{tabular}

Table 3. Active Compound of M. oleifera with Pa value more than 0.7

\begin{tabular}{|c|c|c|}
\hline \multicolumn{3}{|l|}{ Leaves } \\
\hline Compounds & $\mathrm{Pa}$ & Precision \\
\hline Ascorbic-Acid & 0.928 & $53.30 \%$ \\
\hline Beta-Carotene & 0.775 & $97.70 \%$ \\
\hline Kaempferol & 0.856 & $100 \%$ \\
\hline Quercetin & 0.872 & $100 \%$ \\
\hline Tocopherols & 0.927 & $89.80 \%$ \\
\hline \multicolumn{3}{|l|}{ Seeds } \\
\hline Compounds & $\mathrm{Pa}$ & Precision \\
\hline Alpha-Tocopherol & 0.967 & $100 \%$ \\
\hline Beta-Carotene & 0.775 & $97.70 \%$ \\
\hline Delta-Tocopherol & 0.843 & $77 \%$ \\
\hline Gamma-Tocopherol & 0.927 & $89.80 \%$ \\
\hline Tocopherols & 0.927 & $89.80 \%$ \\
\hline \multicolumn{3}{|l|}{ Leaves-Seeds } \\
\hline Compounds & $\mathrm{Pa}$ & Precision \\
\hline Ascorbic-Acid & 0.928 & $53.30 \%$ \\
\hline Beta-Carotene & 0.775 & $97.70 \%$ \\
\hline Kaempferol & 0.856 & $100 \%$ \\
\hline Quercetin & 0.872 & $100 \%$ \\
\hline Tocopherols & 0.927 & $89.80 \%$ \\
\hline Alpha-Tocopherol & 0.967 & $100 \%$ \\
\hline Delta-Tocopherol & 0.843 & $77 \%$ \\
\hline Gamma-Tocopherol & 0.927 & $89.80 \%$ \\
\hline
\end{tabular}

\section{2,2-Diphenyl-1-picrylhydrazil (DPPH) assay}

The values of the percentage of the free radical scavenging activity of nano complex sample of $M$. oleifera in different treatment was represented in Table 4, its graph was exhibited in Figure 1A (without freezedrying) and Figure 1B (freeze-drying). DPPH assay showed that samples that have high antioxidant activity also have high scavenging activity.
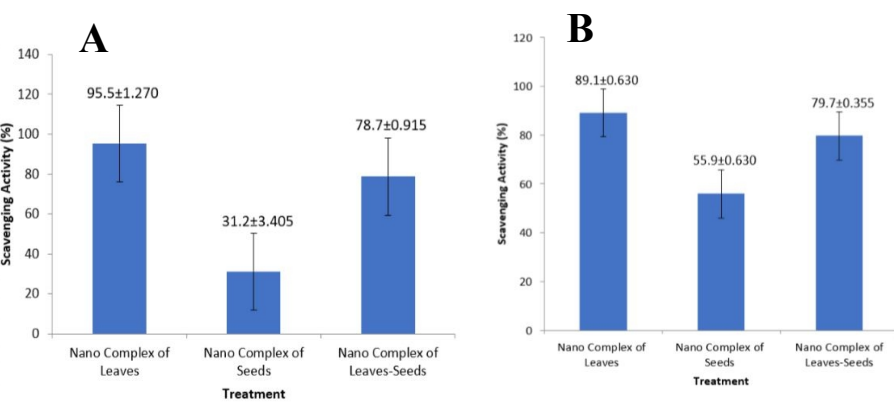

Figure 1. Scavenging activity of nano complex sample, A) Without freeze drying, B) Freeze drying

Table 4. The percentage of DPPH scavenging activity of nano complex sample of $M$. oleifera

\begin{tabular}{lcc}
\hline Type of treatment & Absorbance $(517 \mathrm{~nm})$ & \% Scavenging activity \\
\hline Freeze drying & & \\
$\quad$ Nano complex of leaves & 0.199 & 89.1 \\
$\quad$ Nano complex of seeds & 0.802 & 55.9 \\
Nano complex of leaves-seeds & 0.368 & 79.7 \\
Without freeze drying & & \\
$\quad$ Nano complex of leaves & 0.043 & 95.5 \\
$\quad$ Nano complex of seeds & 0.653 & 31.2 \\
Nano complex of leaves-seeds & 0.202 & 78.7 \\
\hline
\end{tabular}




\section{Discussion}

The results revealed that there were five compounds in $M$. oleifera leaves that have Pa value 0.7, namely Ascorbicacid, Beta-Carotene, Kaempferol, Quercetin, Tocopherols. While the compounds in M. oleifera seeds that have $\mathrm{Pa}$ value more than 0.7 , there were five compounds, namely Alpha-Tocopherol, Beta-Carotene, Delta-Tocopherol, Gamma-Tocopherol, Tocopherols.

PASS prediction data is the value of Probable activity (Pa) which indicates whether the biological activity of a compound is high or not on a laboratory scale. If the $\mathrm{Pa}$ value more than 0.7 then the compound has a high activity value on a laboratory scale. The $\mathrm{Pa}$ value of more than 0.7 means that computationally it will not be much different from the lab test results. If the values are in the range from 0.5 to 0.7 then the compound has moderate activity. If $\mathrm{Pa}$ values more than 0.5 , the compound has a low activity value on a laboratory scale (Chelliah, 2008).

Target prediction analysis of compounds in $M$. oleifera leaves and seeds was carried out using the Hitpick website. Based on the results of the target prediction analysis, it can be seen that the compound has a precision value and Tc to determine the prediction of the accuracy of a compound against its target. Of all the genes that were targeted, one of them had the highest probability or approached $100 \%$. In other words, the target that is closest to $100 \%$ has the possibility of interacting with the active compound of $M$. oleifera when it enters the human body. Of the 10 compounds from the online PASS analysis that had Pa value more than 0.7 , only a few compounds had a target precision value of $100 \%$ or close to $100 \%$. The compound is BetaCarotene targeting RBP4; Kaempferol targeting CYP1B1 and AHR; Quercetin targeting SLCO2B1, SLC16A7, SLC16A1, PIM1, PIK3CG, HCK, DRD4, CYP2C8, CYP1B1, CYP19A1, ATP5A1, AKR1B1, ABCG2, ABCC2, ABCC1, ABCB1; Alpha-Tocopherol targets XDH, PRKCB, PRKCA, NR1I2, GSTA1, ALOX5.

\section{Antioxidant assay}

The fading of the DPPH radical due to the presence of antioxidants is the principle of the DPPH method. The character of free radicals is reduced by transferring electrons or hydrogen atoms to free radicals. The color intensity of the test solution was measured using a UVVis spectrophotometer (Wachidah, 2013). The presence of antioxidant activity in the sample changes the color of the DPPH solution in methanol (Wahdaningsih, 2011). The color change in DPPH is a physical observation of antioxidant activity. The purple color is the original color of DPPH free radicals that have not been reacted with antioxidant compounds and have unpaired electrons. When DPPH is reacted with natural compounds capable of donating hydrogen atoms, the purple color changes to light purple or yellow (Nazilah, 2019).

Based on the observations, the results of the color change of the DPPH solution were mixed with 3 types of samples. The DPPH solution that has not been added to the $M$. oleifera compound sample has a purple color (Fig. 2A.1 and 2B.1). The first sample, DPPH, was added to the $M$. oleifera leaves nano complex compound, there was a significant color change, from purple to yellow (Fig. 2A.2 and 2B.2). The second sample, DPPH, was added with $M$. oleifera seeds nano complex compound, the color changed from purple to white (Fig. 2A.3) and light purple (Fig. 2B.3). The third sample, DPPH, was added to the $M$. oleifera leaves-seed nano complex compound, a significant color change occurred, namely dark purple to yellowish-cloudy white (Fig. 2A.4 and 2B.4). The color change of the sample is seen in Figure 2A (without freeze-drying) and Figure 2B (with freezedrying).

\section{A}

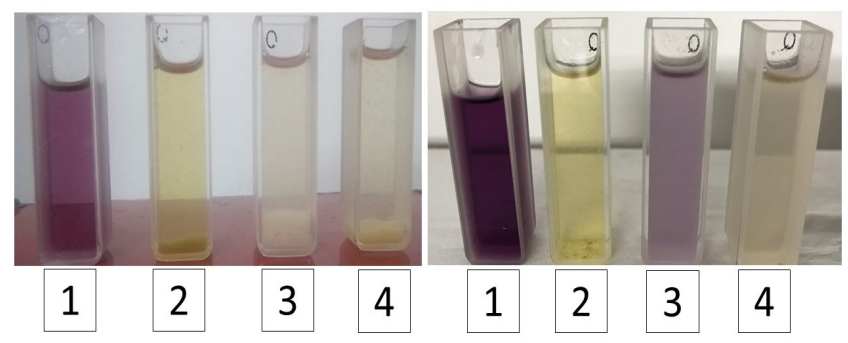

Figure 2. Measurement of samples using UV-Vis spectrophotometry, A) Without freeze drying and, B) Freeze drying.

The high or low antioxidant activity of the samples by the DPPH radical scavenging method is known from the scavenging activity percentage. The greater percentage value of the sample is the higher antioxidant activity. The inhibition process occurs when DPPH radicals react with antioxidant compounds by taking up hydrogen ions (Mubarak, 2017). Based on the results of this study, the percentage value of scavenging was different from each treatment. The first treatment was giving the $M$. oleifera leaves nano complex compound which had an average percentage of scavenging of $95.5 \%$ (before freeze-drying) and 89.1\% (after freeze-drying). The second treatment, namely giving $M$. oleifera seeds nano complex compounds had an average percent scavenging activity of $31.2 \%$ (before freeze-drying) and $55.9 \%$ (after freeze-drying). The third treatment, namely giving $M$. oleifera leaves-seeds nano complex compounds had an average percent scavenging of $78.7 \%$ (before freeze-drying) and 79.7\% (after freeze-drying).

The first treatment by giving $M$. oleifera leaves a nano complex compound was the highest antioxidant activity and the highest percentage of scavenging activity. This is supported by the results of (Pakade et al., 2013) that the total phenol content (TPC) in the M. oleifera leaves sample is twice as much as various other vegetables, and the total flavonoid content (TFC) 3 times more than other vegetables. The results of Mustofa et al (2013) research that $M$. oleifera leaves juice is more effective than $M$. oleifera fruit in absorbing heavy metals through the UVAL method. Based on the research arranged by Nobossé et al (2018), the free radical inhibitory activity of $M$. oleifera leaves has a positive correlation with chlorophyll, TFC, and TPC. Metal reduction activity is also supported by research by Khalofah et al (2019) that the application of M. oleifera leaves extract to lettuce can reduce the effects of metal 
cadmium chloride $(\mathrm{CdCl} 2)$ and can increase tolerance and resistance to cadmium metal.

The second treatment by giving $M$. oleifera seeds nano complex compounds was the lowest antioxidant activity and the lowest percentage of scavenging activity. However, although the lowest percent inhibition results were shown in the second treatment, based on the research of Salman (2018) the results of the free radical inhibition test with the DPPH method of raw M. oleifera seeds flour had the highest antioxidant activity and the lowest was boiled $M$. oleifera seeds flour. In the results of Putri's study (2018), it was also stated that the addition of a $50 \%$ concentration of natural coagulant of $M$. oleifera seeds in making tofu showed the highest antioxidant activity through the DPPH method.

The inhibition percentage obtained from the third treatment has a higher value than the second treatment. This is because the compound in the third treatment is a compound from $M$. oleifera leaves and seeds so that its antioxidant activity is higher than in the second treatment. However, the percent scavenging value of the third treatment was lower than the first treatment. Based on the results of in silico analysis, it can also be seen that many active compounds in $M$. oleifera leaves have a $\mathrm{Pa}$ value of more than 0.7 and a target precision value of $100 \%$ or close to $100 \%$. Meanwhile, there is only one active compound in $M$. oleifera seeds that has a $\mathrm{Pa}$ value of more than 0.7 and a target precision value of $100 \%$ or close to $100 \%$. This is what causes the M. oleifera leaves-seed mixture treatment to have a lower inhibition value when compared to the $M$. oleifera leaves treatment. This study also only used one type of ratio for the concentration of the mixed sample (1:1) with a weight of $5 \mathrm{~g}$ of leaves and $5 \mathrm{~g}$ of seeds. From these reasons, it can be possible that the comparison has not been effective so that the results are lower than the first treatment. Therefore, further research can be carried out with various types of comparisons to find out the most effective comparison results.

\section{Observation of nano complex plant sample}

The observation of the nano complex plant sample was observed by a microscope with type Olympus BX43. When observing Nano complex leaves samples before freeze-drying, cells still looked intact and normal (Figure $3 \mathrm{~A})$. In contrast to the freeze-dried sample, the cells are seen under the microscope turn into crystals (Figure $3 \mathrm{~B}$ ). Based on Greaves (1960), more rapid freezing will lead to the formation of small crystals within the cells. At the same time, these crystals may cause considerable deformation of the cells. According to Sukmaningsih et al (2018), crystal is a material that has an organized three-dimension regular pattern with a directional atomic bonding and a tight order. Sukmaningsih et al (2018) investigated the existence of crystalline in the freezedried Java plum fruit. The freeze-dried java plum fruit powder process indicating a chemical reaction did not exist. However, there was a possibility that the position of atoms nearby formed an order of a crystal. The results of observations conducted by using a polarizing microscope indicated that the fruit contained a crystal.
Linkage of in silico studies and antioxidant activity tests

Based on the theory, the more complex compounds will have higher antioxidant activity. According to Jayanti et al (2018), it is highly probable that the complex of caffeine and ovalbumin has strong free radical scavenging activity. However, based on the results of research in the laboratory, leaves-seeds nano complex compounds have lower antioxidant activity than leaves nano complex compounds. For this reason, an in silico analysis was arranged to establish the prediction of the antioxidant activity of $M$. oleifera leaves and seeds. Based on in silico analysis, there are fewer compounds in the leaves than in the seeds, but almost all of the $\mathrm{Pa}$ values have a $\mathrm{Pa}$ value of more than 0.7 . While the compounds in the seeds, although many have a Pa value 0.7 , there is still a possibility that these compounds can complement.

The in silico study was carried out as a reinforcement of laboratory tests. Based on in silico studies, the compounds in $M$. oleifera have the potential for antioxidant activity and free radical scavenging, which can be seen from the online PASS results. Antioxidant activity tests in the laboratory have shown that the antioxidant activity of $M$. oleifera complex nano compounds from leaves and seeds has differences, which can be seen from the percentage of inhibition. The difference in the level of antioxidant activity in laboratory tests is related to in silico studies. The in silico study showed that $M$. oleifera leaves compounds had 3 compounds with a $\mathrm{Pa}$ value of more than 0.7 and a target prediction of $100 \%$ or close to $100 \%$, namely BetaCarotene, Kaempferol, Quercetin. While the M. oleifera seed compound only has 2 compounds with a Pa value of more than 0.7 and a target prediction of $100 \%$ or close to $100 \%$, namely Alpha-Tocopherol and Quercetin compounds. That is represented in Table 3.

In conclusion, the $M$. oleifera leaves-seed compound nano complex has antioxidant potential both in silico and in the wet laboratory. In silico studies show that 3 compounds in $M$. oleifera leaves have an important role in antioxidant activity, namely beta-carotene, kaempferol, quercetin. While the $M$. oleifera seeds obtained 2 compounds, namely alpha-tocopherol, beta-carotene. The antioxidant activity tests of the leaves, seeds, and leavesseeds combination before freeze-drying were $95.5 \%$, $31.2 \%, 78.7 \%$, and $89.1 \%, 55.9 \%, 79.7 \%$ after freezedrying, respectively. The most effective in DPPH scavenging as free radical was the nano complex compound of $M$. oleifera leaves.
A

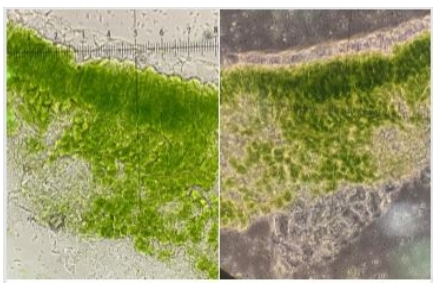

B

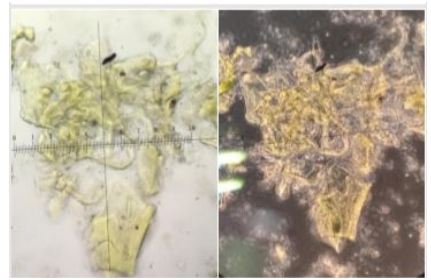

Figure 3. Microscopic observation of leaf samples, A) before freeze drying, B) after freeze drying. 


\section{Acknowledgment}

The HI-Ma 2019 University of Islam Malang funded the research.

\section{References}

Boonchum, W., Peerapornpisal, Y., Vacharapiyasophon, P., Pekkoh, J., Pumas, C., Jamjai, U., Amornlerdpison, D., Noiraksar T., \& Kanjanapoth, D. (2011). Antioxidant activity of some seaweed from the gulf of Thailand. International Journal Agriculture of Biology, 13(1), 95-99.

Chelliah, D. A. (2008). Biological activity prediction of an ethno medicinal plant Cinnamomum camphora through bioinformatics. Ethnobotanical Leaveslets, 12, 181-190.

Dewandari, K. T., Yuliani, S., \& Yasni, S. (2013). Ekstraksi dan karakterisasi nanopartikel ekstrak sirih merah (Piper crocatum). Jurnal Pascapanen, 10(2), 58-65.

Ekins, S., Mestres, J., \& Testa, B. (2007). In silico pharmacology for drug discovery: Application to targets and beyond. British Journal Pharmacology, 152(1), 21-37.

Fahey, J. W. (2005). Moringa oleifera: a review of the medical evidence for its nutritional, therapeutic, and prophylactic properties. Trees for Life Journal, 1(5), 1-15.

Greaves, R. I. N. (1960). Preservation of living cells by freeze-drying. Annals of the New York Academy of Sciences, 85(2), 723-728.

Jayanti, G. E., Widyarti, S., Sabarudin, A., \& Sumitro, S. B. (2018). Egg white albumin form complex with aspirin and caffeine and its role as free radical scavenger. Asian Journal of Pharmaceutical and Clinical Research, 11(7), 340-344.

Khalofah, A., Bokhari, N. A., Migdadi, H. M., \& Alwahibi, M. S. (2019). Antioxidant responses and the role of Moringa oleifera leaves extract for mitigation of cadmium stressed Lepidium sativum L. South African Journal of Botany, 129, 341-346.

Kowalczyk, B., Lagzi, I., \& Grzybowski, B. A. (2020). Nanoseparations: Strategies for size and/or shape-selective purification of nanoparticles. Current Opinion in Colloid \& Interface Science, 16(2011), 135-148.

Laandrault, N., Pouchert, P., Ravel, P., Gasc, F., Cros, G., \& Teissedre, P.L. (2001). Antioxidant activities and phenolic level of French wines from different varieties and vintages. Journal of Agricultural and Food Chemistry, 49(7), 3341-3343.

Miles, A. (2009). Complexity in medicine and healthcare: People and systems, theory and practice. Journal of Evaluation in Clinical Practice, 15(3), 409-410.

Mubarak, K., Natsir, H., Wahab, A. W., \& Satrimafitrah, P. (2017). Analisis kadar $\alpha$-tokoferol (vitamin E) dalam daun kelor (Moringa oleifera Lam) dari daerah pesisir dan pegunungan serta potensinya sebagai antioksidan. Kovalen, 3(1), 78-88.

Mustofa, A. N., Rahayu, T., \& Hayati, A. (2013). Penggunaan perasan buah dan daun mengkudu (Morinda citrifolia L), kelor (Moringa oleifera) dan sirsat (Annona muricata) untuk observasi air tercemar uap merkuri. Jurnal Ilmiah Biosaintropis, 26-32.

Nazilah, N. R. K. (2019). Uji aktivitas antioksidan dan skrining potensi antikanker ekstrak metanol buah kurma ajwa (Phoenix dactylifera). Skripsi. Fakultas Sains dan Teknologi, Universitas Islam Negeri Sunan Ampel, Surabaya

NanoPartz. (2020). Centrifuge speeds. Retrived from https://www.nanopartz.com/gold-nanoparticles-propertiescentrifuge-speeds.asp.

Nobossé, P., Fombang, E. N., \& Mbofung, C. (2018). Effects of age and extraction solvent on phytochemical content and antioxidant activity of fresh Moringa oleifera L. leaves. Food Science and Nutrition, 6(8), 2188-2198.

Oyinloye, T. M., \& Yoon, W. B. (2020). Effect of freeze-drying on quality and grinding process of food produce: A review. Processes, 8(354), 1-23.

Padayachee, B., \& Baijnath, H. (2019). An updated comprehensive review of the medicinal, phytochemical and pharmacological properties of Moringa oleifera. South African Journal of Botany, 129, 304-316.
Pakade, V., Cukrowska, E., \& Chimuka, L. (2013). Comparison of antioxidant activity of Moringa oleifera and selected vegetables in south africa. South African Journal of Science, $109(3 / 4), 1-5$

Patil, V. V., Dandekar, P. P., Patravale, V. B., \& Thorat, B. N. (2010). Freeze drying: Potential for powdered nanoparticulate product. Drying Technology, 28(5), 624-635.

Pezzuto, J. M., \& Park, E. J. (2002). Autooxidation and antioxidants In: Swarbrick J, Boylan JC, editors. Encyclopedia of pharmaceuticals technology. Vol. 1. 2nd ed. New York: Marcel Dekker Inc.

Putri, S. H., Ardiansah, I., \& Hanidah, I. (2018). Antioksidan pada produk tahu hasil koagulasi menggunakan biji kelor (Moringa oleifera L.). Jurnal Teknotan, 12(1), 73-78.

Salman, A. N. (2018). Aktivitas antioksidan dan sifat fisik tepung dari biji kelor (Moringa oleifera) hasil pemanasan basah. Skripsi. Fakultas Teknologi Pertanian, Institut Pertanian, Bogor.

Sukmaningsih, A. A. S. A., Permana, S., Santjojo, D. J. D. H., Wardoyo, A. Y. P., \& Sumitro, S. B. (2018). Investigating natural transition metal coordination anthocyanin complex in java plum (Syzygium cumini) fruit as free radical scavenging. Rasayan Journal of Chemistry, 11(3), 1193-1203.

Sumitro, S. B. (2011). Reconsider our understanding on biological system (a new concept driven by nanobiology and complexity science). Prosiding Seminar Nasional VII Pendidikan Biologi FKIP UNS. Surakarta. Hal. 1-14.

Vyas, S., Kachhwaha, S., \& Kothari, S. L. (2015). Comparative analysis of phenolic contents and total antioxidant capacity of Moringa oleifera Lam. Pharmacognosy Journal, 7(1), 44-51.

Wachidah, L. N. (2013). Uji Aktivitas Antioksidan serta Penentuan Kandungan Fenolat dan Flavonoid Total dari Buah Parijoto (Medinilla speciosa Blume). Skripsi. Fakultas Kedokteran dan Ilmu Kesehatan, Universitas Syarif Hidayatullah, Jakarta.

Wahdaningsih, S., Setyowati, E. P., \& Wahyuono, S. (2011). Aktivitas penangkap radikal bebas dari batang pakis (Alsophila glauca $\mathrm{J}$. Sm). Majalah Obat Tradisional, 16(3), 156-160.

Wibawa, I. P. A. H, Andila, P. S., Saraswaty, V., \& Tirta, I. G. (2020). Phytochemical properties and antioxidant activities of the leaves extracts of Boenninghausenia albiflora (Hook.) Rchb. ex. Meisn. (Rutaceae). Journal of Biological Researches, 25(2), 12-17. 